\title{
A Prospective Observational Study of Hypomagnesemia in Critically Ill Paediatric Patients
}

\section{Channanayaka Chandrashekhar ${ }^{1}$, Reshmi Pillai ${ }^{1}$, Prajwala Hassan Vasudev', Tirin Babu ${ }^{2}$ and George Mathew Panachiyil ${ }^{2}$}

${ }^{1}$ Department of Paediatrics, JSS Medical College and Hospital, JSS Academy of Higher Education and Research, Mysuru, Karnataka, India

${ }^{2}$ Department of Pharmacy Practice, JSS College of Pharmacy, JSS Academy of Higher Education and Research, Mysuru, Karnataka, India

\section{Correspondence:}

Channanayaka Chandrashekhar

Department of Paediatrics

JSS Medical College and Hospital,

JSS Academy of Higher Education and

Research,

Mysuru, Karnataka, India

E-mail: chandruped23@gmail.com

DOI: $10.3126 /$ jnps.v40i2.28627

Submitted on:2020-04-27

Accepted on: 2020-06-14

Acknowledgements: None

Funding: Nil

Conflict of Interest: None

Permission from IRB: Yes

To cite this article: Chandrashekhar $\mathrm{C}$, Pillai R, Vasudev PH, Babu T, Panachiyil GM. A prospective observational study of hypomagnesemia in critically ill paediatric patients. J Nepal Paediatr Soc. 2020;40(2):67-71.

\section{ABSTRACT}

Introduction: Magnesium deficiency, a common finding in critically ill patients, is associated with increased need for respiratory support, increased duration of ICU stay and mortality. The primary objective of our study is to assess the prevalence of hypomagnesaemia in critically ill children (requiring inotropic support, respiratory support, and fluid resuscitation) on admission in the Paediatric Intensive Care Unit (PICU). The secondary objective is to evaluate its relationship with the length of hospital stay and mortality.

Methods: This prospective observational study was conducted in the PICU of a tertiary care hospital. In this study, serum magnesium levels at admission were measured along with other laboratory tests, after informed consent. Serum magnesium levels were assayed in our laboratory. The normal range of serum magnesium in our lab is 1.7-2.7 mg/dl. During admission in PICU, there was follow-up for ionotrope administration, need for mechanical ventilation, APACHE II score, PICU length of stay and mortality.

Results: In this study, 350 critically ill children requiring hemodynamic / respiratory support were chosen. However, 83 children were excluded from study as they were discharged against medical advice. The prevalence of hypomagnesemia in this study was $43.4 \%$. There was no significant association between hypomagnesemia, duration of hospital stay and mortality.

Conclusion: Hypomagnesaemia is a common finding in critically ill paediatric patients, however there is no significant association noted in regards to length of hospital stay, duration of mechanical ventilation, inotropic support and mortality.

Key Words: hypomagnesemia; PICU; serum magnesium

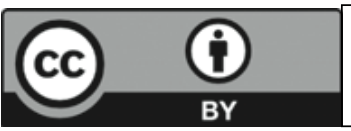

This work is licensed under creative common attribution 3.0 license 


\section{INTRODUCTION}

Magnesium ( $\mathrm{Mg}$ ) is an important cation, and is necessary for normal physiologic function. ${ }^{1}$ It plays a key role in various metabolic processes such as cellular energy production, neurotransmission, enzymatic reactions and many other body and cell functions. ${ }^{2}$ Magnesium deficiency is a common phenomenon in critical care setting and this deficiency often develops in a wide variety of medical conditions such as protein-energy malnutrition, malabsorption, hypoalbuminemia, sepsis, etc., which are frequently seen in children. ${ }^{3,4}$ It should be stressed that serum magnesium does not necessarily reflect total body magnesium, since the cation is primarily intracellular. ${ }^{5}$ The etiology of hypomagnesemia in critical illness may involve a number of mechanisms such as decreased intake, increased renal or gastrointestinal losses and altered intracellular-extracellular distribution. ${ }^{6}$ Earlier studies have revealed wide variation in prevalence of hypomagnesemia in the intensive care unit setting. Some studies have reported increased duration of hospital stay and requirement of respiratory support in hypomagnesemic patients.

The primary objective of the study is to assess the prevalence of hypomagnesaemia in critically ill children (requiring ionotropic support, respiratory support, and fluid resuscitation) on admission in the PICU. The secondary objective is to evaluate its relationship with the length of hospital stay and mortality.

\section{METHODS}

This prospective observational study was conducted in the PICU of a tertiary care hospital in South India for two years (September 2017 to October 2019) after receiving due approval from the institutional human ethical committee. All included critically ill patients (requiring ionotropic

Table 1. Magnesium Levels versus ionotropic support

\begin{tabular}{|lrr|}
\hline Group & Number & $\begin{array}{c}\text { Those requiring } \\
\text { ionotropic support }\end{array}$ \\
\hline Total & 267 & $103(38.6 \%)$ \\
Hypomagnesemia & 116 & $42(36.4 \%)$ \\
Normomagnesemia & 151 & $61(40.4 \%)$ \\
\hline
\end{tabular}

support, fluid resuscitation, respiratory support) admitted to PICU were aged one month to 18 years, and their estimated PICU stay was more than 48 hours. Patients were excluded from the study if they had received blood products, magnesium, calcium infusions before sampling and with medical history of congenital renal wasting syndromes like Bartter and Gittleman. In this study, after informed consent, serum magnesium levels at admission were measured along with other laboratory tests. Serum magnesium levels were assayed in our laboratory by xylidyl blue method using Toshiba $120 \mathrm{FR}$ automated analyser, with the normal range of serum magnesium being $1.7-2.7$ $\mathrm{mg} / \mathrm{dl}$. During admission in PICU, there was constant follow-up for ionotrope administration, need for mechanical ventilation, APACHE II score, PICU length of stay, and mortality.

With the absolute error/precision of $5 \%$ (corresponding to a confidence interval of $95 \% \pm$ $5 \%$ ) at type 1 error of $5 \%$, the sample size was calculated from the prevalence of $44 \%$ from the previous studies and this size which came out to be 375 , which was rounded off to 350 .

The data were collected in excel sheet and were analysed using SPSS version 22 for Microsoft Windows Software. P - value $<.05$ was considered statistically significant - the following statistical tests were used for data analysis such as ChiSquare Test, t-test and ANOVA test.

\section{RESULTS}

A total of 267 patients [175 (65.5\%) boys] with PICU admission, aged one month to 18 years were enrolled from 350 children after exclusion of 83 children from the study as they were discharged against medical advice. There was no significant

Table 2. Magnesium levels versus ventilatory support

\begin{tabular}{|lrr|}
\hline Group & Number & $\begin{array}{r}\text { Those requiring } \\
\text { respiratory Support }\end{array}$ \\
\hline Total & 267 & $118(44.2 \%)$ \\
Hypomagnesemia & 116 & $48(41.4 \%)$ \\
Normomagnesemia & 151 & $70(46,4 \%)$ \\
\hline
\end{tabular}


Table 3. Magnesium levels versus mortality

\begin{tabular}{|lcr|}
\hline Group & Numbers & \multicolumn{1}{c}{ Mortality } \\
\hline Total no of case & 267 & $49(18.4 \%)$ \\
$\begin{array}{l}\text { No of case with } \\
\text { hypomagnesemia }\end{array}$ & 116 & $21(18.1 \%)$ \\
$\begin{array}{l}\text { No of case with } \\
\text { normomagnesemia }\end{array}$ & 151 & $28(18.4 \%)$ \\
\hline
\end{tabular}

association between specific age distribution, gender distribution and magnesium levels.

Out of the 267-study population, 116 were found to have hypomagnesemia with prevalence of $43.4 \%$. Normomagnesemia was seen in 151 patients with prevalence of $56.6 \%$. The minimum observed serum magnesium value was $1.20 \mathrm{mg} / \mathrm{dl}$ and the maximum observed value was $4.7 \mathrm{mg} / \mathrm{dl}$.

Of the 267 patients, $36.2 \%$ of hypomagnesemic children and $40.4 \%$ of normomagnesemic children required ionotropes. There was no significant association between hypomagnesemia and ionotropic support (Table 1).

Of total 267 cases, the total number of patients requiring ventilatory support in hypomagnesemic group was $48(41.4 \%)$ and in normomagnesemia group was $70(46.4 \%)$. There was no significant association between hypomagnesemia and ventilatory support (Table 2).

Among 267 cases, 21 patients in hypomagnesemic group died with mortality rate of $18.1 \%$. Whereas 28 patients died in normo-magnesemia group with mortality rate of $18.5 \%$. The association between magnesium levels and mortality was done using chi- square test. Death as an end point had no significant association with hypomagnesemia (Table 3 and Table 4).

Table 5. Magnesium values versus duration of stay

\begin{tabular}{|c|c|c|}
\hline Group & $\begin{array}{l}\text { Mean duration of } \\
\text { stay }\end{array}$ & Median \\
\hline Hypomagnesemia & 7.819 & 6.0 \\
\hline Normomagnesemia & 9.165 & 7.0 \\
\hline
\end{tabular}

Table 4. risk estimate

\begin{tabular}{|lccc|}
\hline Odds ratio & Value & \multicolumn{2}{c|}{$\begin{array}{c}\text { 95\% Confidence } \\
\text { Interval }\end{array}$} \\
\cline { 2 - 4 } & & Lower & Upper \\
\hline $\begin{array}{l}\text { Odds Ratio for } \\
\text { outcome (Dis / } \\
\text { Death) }\end{array}$ & 1.030 & 0.551 & 1.926 \\
$\begin{array}{l}\text { For cohort } \mathrm{Mg} \\
<1.70\end{array}$ & 1.017 & 0.712 & 1.453 \\
$\begin{array}{l}\text { For cohort } \mathrm{Mg} \\
>1.71\end{array}$ & 0.987 & 0.754 & 1.292 \\
$\begin{array}{l}\text { No of valid cases } \\
\text { Non }\end{array}$ & 267 & & \\
\hline
\end{tabular}

The duration of mean hospital stay in hypomagnesemic group was 7.819 days and in normomagnesemia group was 9.16 days (Table 5 and Table 6). There was no statistical significance $(\mathrm{p}$ value $=0.927)$ between hypomagnesemia and duration of stay.

Mean APACHE II value in hypomagnesemic group was 21.7 and in normomagnesemia group was 22.9. Hypomagnesemia was not associated with a higher APACHE II score (Table 7).

\section{DISCUSSION}

Results of this study showed the proportion of hypomagnesemia in critically ill paediatric patients comparable to other studies and couldn't find any significant association of magnesium level with length of hospital stay, need for a mechanical ventilator, and mortality. A total of 350 critically ill children who satisfied the inclusion criteria were

Table 6. Risk estimate

\begin{tabular}{|c|c|c|c|}
\hline \multirow[t]{2}{*}{ Odds ratio } & \multirow[t]{2}{*}{ Value } & \multicolumn{2}{|c|}{$\begin{array}{l}\text { 95\% Confidence } \\
\text { Interval }\end{array}$} \\
\hline & & Lower & Upper \\
\hline $\begin{array}{l}\text { Odds ratio for } \\
\text { duration of stay } \\
(<5 \mathrm{~d} />5 \mathrm{~d})\end{array}$ & 1.224 & 0.744 & 2.014 \\
\hline $\begin{array}{l}\text { For cohort } \mathrm{Mg} \\
<1.7\end{array}$ & 1.120 & 0.849 & 1.476 \\
\hline $\begin{array}{l}\text { For cohort } \mathrm{Mg} \\
>1.7\end{array}$ & 0.915 & 0.732 & 1.143 \\
\hline $\mathrm{N}$ of valid cases & 267 & & \\
\hline
\end{tabular}


Table 7. Magnesium levels versus APACHE II

\begin{tabular}{|c|c|c|}
\hline Group & $\begin{array}{l}\text { Mean APACHE } \\
\text { II score }\end{array}$ & Median \\
\hline Hypomagnesemia & 21.79 & 22.0 \\
\hline Normomagnesemia & 22.086 & 22.0 \\
\hline
\end{tabular}

chosen for the study. However, 83 children were excluded from the study as they were discharged against medical advice.

Analysis of serum magnesium levels showed hypomagnesemia in $116(43 \%)$ children and normomagnesemia in 151 (57\%) children. These results are in agreement with Kumar S et al., who reported prevalence of hypomagnesemia to be $53 \%$ and normomagnesemia to be $47 \% .^{7}$ Maximum measured serum magnesium value was $4.3 \mathrm{mg} / \mathrm{dl}$ and lowest measured was $1.1 \mathrm{mg} / \mathrm{dl}$. The prevalence of hypomagnesemia was higher in studies which measured total serum magnesium than in studies which measured ionised magnesium (Huijigen et al. 14\%). ${ }^{8}$

In relation to length of stay in PICU, the mean duration of stay of patients with hypomagnesemia was 7.68 days and normomagnesemia was 8.5 days. This was similar to findings by Limaye et al. who found no difference in mean duration of PICU stay among hypomagnesemic $(8+/-7.92$ days $)$ and normomagnesemia $(6.17+/-3.84$ days $)$ groups. ${ }^{9}$ Increased duration of PICU stay among hypomagnesemic children was reported by Safavid et al and Kumar et al. ${ }^{7,10}$ No correlation was found between duration of hospital stay and magnesium levels in the study done by Chernow et al. and Soliman et al. ${ }^{11,12}$

In this study, 76 (47\%) of hypomagnesemic children required ventilatory support and 93 (49\%) of normomagnesemia children required ventilatory support. Kumar et al. reported that $56.86 \%$ of hypomagnesemic children required ventilatory support and $24.3 \%$ of normomagnesemia children required ventilatory support. Many studies have reported increased frequency and duration of ventilatory support among hypomagnesemic patients, as hypomagnesemia is a known cause of muscle weakness and respiratory failure. ${ }^{7}$ The present study found that $42 \%$ of hypomagnesemic children required ionotropic support and $44 \%$ of normomagnesemia children required ionotropic support. There was no significant association between hypomagnesemia and need for ionotrope.

In the present study mortality rate among hypomagnesemic group was $18.1 \%$ and among normomagnesemia group was $18.5 \%$. This is in accordance with study reported by Guerin et al. who showed that there was no association between hypomagnesemia and increased mortality. ${ }^{13}$ In hypomagnesemic group, the mean APACHE II score was 22.16 and in normomagnesemic group the mean APACHE II score was 22.09. This is in accordance with findings of Limayee et al., Guerin et al., Chernov et al., Soliman et al. and Rubeiz et al., who found that there was no association of higher APACHE II score among hypomagnesemic children. ${ }^{9,11-14}$ In contrary, Safavi et al. has found association between hypomagnesemia and high APACHE II score. ${ }^{10}$

Our study has some limitations. The ionised magnesium levels were not measured in this study, which could have been more accurate interpretation and substantial number of patients (83) were discharged against medical advice. The significance of association between hypomagnesemia and its relation with length of hospital stay and mortality rate could not be determined.

\section{CONCLUSIONS}

Hypomagnesemia is a common finding in critically ill patients and it needs to be identified and treated. In the present study, the prevalence of hypomagnesemia was $43.2 \%$ and there was no significant association observed between hypomagnesemia, duration of hospital stay and mortality. However, many studies done in adult patients and few studies done in paediatric patients show a significant association. So further research on this topic with a large number of sample size should be performed in order to confirm this association. 


\section{REFERENCES}

1. Saleem AF, Haque A. On admission hypomagnesemia in critically ill children: Risk factors and outcome. IJP. 2009;76(12):1227-30. DOI: https://doi.org/10.1007/s12098-009-0258-z

2. Wagner CA. Disorders of renal magnesium handling explain renal magnesium transport. J nephrol. 2007;20(5): 507-10. PMID: 17918133

3. Tong GM, Rude RK. Magnesium deficiency in critical illness. J intensive care med. 2005;20(1):3-17. DOI: https:// doi.org/10.1177/0885066604271539

4. Singhi SC, Singh J, Prasad R. Hypo-and Hypermagnesemia in an Indian Paediatric Intensive Care Unit. J trop paediatrics. 2003;49(2):99-103. DOI: https://doi.org/10.1093/tropej/49.2.99

5. Hansen B-A, Bruserud O. Hypomagnesemia in critically ill patients. J Intensive Care. 2018;6(1):21. DOI: https:// doi.org/10.1186/s40560-018-0291-y

6. Swaminathan R. Magnesium metabolism and its disorders. Clin Biochem Rev. 2003;24(2):47. PMID: 18568054

7. Kumar S, Honmode A, Jain S, Bhagat V. Does magnesium matter in patients of Medical Intensive Care Unit: A study in rural Central India. Indian J Crit Care Med. 2015;19(7):379. DOI: https://doi.org/ $10.4103 / 0972-5229.160272$

8. Huijgen HJ, Soesan M, Sanders R, Mairuhu WM, Kesecioglu J, Sanders GT. Magnesium Levels in Critically Ill Patients. Am J Clin Pathol. 2000;114(5):688-95. DOI: https://doi.org/10.1309/JR9Y-PPTX-AJTC-QDRD

9. Limaye CS, Londhey VA, Nadkart MY, Borges NE. Hypomagnesemia in critically ill medical patients. J Assoc Physicians India. 2011;59:19-22. PMID: 21751660

10. Safavi M, Honarmand A. Admission hypomagnesemia - Impact on mortality or morbidity in critically ill patients. Middle East J Anaesthesiol. 2007;19:645-60. PMMID: 18044292

11. Chernow B, Bamberger S, Stoiko M, Vadnais M, Mills S, Hoellerich V, et al. Hypomagnesemia in patients in postoperative intensive care. Chest. 1989;95:391-7. DOI: https://doi.org/10.1378/chest.95.2.391

12. Soliman HM, Mercan D, Lobo SS, Mélot C, Vincent JL. Development of ionised hypomagnesemia is associated with higher mortality rates. Crit Care Med. 2003;31:1082-7. DOI: https://doi.org/10.1097/01.CCM. 0000060867.17556.A0

13. Guérin C, Cousin C, Mignot F, Manchon M, Fournier G. Serum and erythrocyte magnesium in critically ill patients. Intensive Care Med. 1996;22:724-7. DOI: https://doi.org/10.1007/BF01709512

14. Rubeiz GJ, Thill-Baharozian M, Hardie D, Carlson RW. Association of hypomagnesemia and mortality in acutely ill medical patients. Crit Care Med. 1993;21:203-9. DOI: https://doi.org/10.1097/00003246-199302000-00010 